\title{
ARTIGOS
}

\section{FORMAÇÃO ACADÊMICA E ATUAÇÃO PROFISSIONAL DE DOCENTES EM EDUCAÇÃO: USP E UNICAMP}

HELENA SAMPAIO

ILARA SANCHEZ

\section{RESUMO}

A partir do estudo das trajetórias de formação acadêmica e profissional de docentes de duas universidades públicas paulistas, o artigo aborda a relação entre setor público e setor privado no sistema de ensino superior no Brasil e, em especial, no sistema paulista. A fonte de dados é o banco de currículos do Conselho Nacional de Desenvolvimento Científico e Tecnológico - CNPq - Plataforma Lattes. Com base nos resultados, apontamos: i) o imbricamento das trajetórias individuais de formação acadêmica e de atuação profissional dos docentes pesquisados com os processos de expansão e diferenciação da oferta de ensino superior no país; ii) a existência de padrões de circulação dos docentes pesquisados no sistema nacional de ensino superior, os quais revelam acentuadas endogenia acadêmica e hierarquização das instituições públicas e privadas.

ENSINO SUPERIOR • PROFESSORES • SETOR PÚBLICO • SETOR PRIVADO

\section{ACADEMIC EDUCATION AND \\ PROFESSIONAL PRACTICE OF TEACHERS \\ IN EDUCATION: USP AND UNICAMP}

\section{ABSTRACT}

Based on the study of the academic and professional training paths of teachers at two public universities in São Paulo, this article discusses the relationship between the public and the private sectors in the higher education system in Brazil and, in particular, in São Paulo. The data source is the curriculum vitae database of the Conselho Nacional de Desenvolvimento Científico e Tecnológico [National Council for Scientific and Technological Development] - CNPq-, Lattes Platform. Based on the results, we show: i) the overlapping of the individual paths of academic training and professional practice of the teachers surveyed, with the processes of expansion and differentiation of the offer of higher education in the country; ii) the existence of patterns of movement of the teachers surveyed in the national system of higher education, which show marked academic endogeny and hierarchization of the public and private institutions. 


\section{FORMATION ACADÉMIQUE ET PERFORMANCE PROFESSIONELLE D'ENSEIGNANTS DE L'ÉDUCATION: USP ET UNICAMP}

RÉSUMÉ

Cet article aborde la question du rapport entre le secteur public et le secteur privé dans le système d'enseignement supérieur au Brésil, et plus particulièrement à São Paulo à partir de l'étude des trajectoires de formation académique et professionnelle d'enseignants de deux universités publiques de l'état de São Paulo. La source des données est la base de curriculum vitae du Conselho Nacional de Desenvolvimento Científico e Tecnológico [Conseil National de Développement Scientifique et Technologique] - CNPq - Plateforme Lattes. Appuyés sur les résultats, nous signalons: i) l'imbrication des trajectoires individuelles de formation académique et d'exercice professionnel des enseignants étudiés avec les processus d'expansion et de différentiation de l'offre d'enseignement supérieur dans le pays; ii) l'existence de patrons de circulation des ces enseignants dans le système national d'enseignement supérieur, qui révélent le caractère hautement endogène du monde académique et la hiérarchisation des institutions publiques et privées d'enseignement supérieur.

ENSEIGNEMENT SUPERIEUR • ENSEIGNANTS • SECTEUR PUBLIC • SECTEUR PRIVE

\section{FORMACIÓN ACADÉMICA Y ACTUACIÓN PROFESIONAL DE DOCENTES EN EDUCACIÓN: USP Y UNICAMP}

RESUMEN

A partir del estudio de las trayectorias de formación académica y profesional de docentes de dos universidades públicas paulistas, el artículo aborda la relación entre sector público y sector privado en el sistema de enseñanza superior en Brasil $y$, en especial, en el sistema paulista. La fuente de datos es el banco de currículos del Conselho nacional de Desenvolvimento Científico e Tecnológico [Consejo Nacional de Desarrollo Científico y Tecnológico]-CNPq-Plataforma Lattes. Con base en los resultados, observamos: i) el envolvimiento de las trayectorias individuales de formación académica y de actuación profesional de los docentes investigados con los procesos de expansión y diferenciación de la oferta de enseñanza superior en el país; ii) la existencia de pautas de circulación de los docentes investigados en el sistema nacional de enseñanza superior, los cuales revelan acentuadas endogenía académica y jerarquización de las instituciones públicas y privadas. 


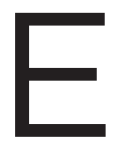

STE ARTIGO TRATA DA RELAÇÃo ENTRE ENSINO SUPERIOR PÚBLICO E PRIVADO NO sistema de ensino superior brasileiro da perspectiva da circulação de seus docentes. A questão será discutida a partir do exame das trajetórias de formação acadêmica - na condição de alunos de graduação e de pós-graduação - e de atuação profissional de docentes hoje vinculados a duas universidades públicas.

Uma das hipóteses do estudo é que o processo de expansão do sistema de ensino superior nos últimos trinta anos no Brasil, entendido como crescimento da demanda e da oferta do ensino de graduação e de pós-graduação (mestrado e doutorado), resultou em mais opções para a formação pós-graduada e também no incremento do número de postos de trabalho no sistema nacional para titulados mestres e doutores.

estudantes de ensino superior; em 2010, já eram 5.449.120 (BRASIL, 2015a)

2

Em 2000, as matrículas de mestrado e as de doutorado eram, respectivamente 60.425 e 32.900. Naquele ano, titularam-se 17.61 mestres e 5.318 doutores. Em 2010, havia 98.611 alunos matriculados em programas de mestrado acadêmico e 64.588 em programas de doutorado. Titularam-se, em 2010, 36.247 mestres e 10.123 rior no país passa por grandes mudanças (MARTINS, 2002; NEVES, 2003; SAMPAIO, 2000; SCHWARTZMAN, 2014). Entre 1980 e 2010, período de formação e/ou de iníco de atuação profissional de boa parte dos docentes que participaram desta pesquisa, o número de matrículas de graduação, estagnado há alguns anos em torno de um 1,4 milhão, atingiu quase 5,5 milhões (BRASIL, 2015a). ${ }^{1}$ Já o número de matrículas na pós-graduação stricto sensu (mestrado acadêmico e doutorado) passou de 93.325, em 2000, para 163.199, em 2010. ${ }^{2}$ A distribuição das matrículas de graduação e de pós-graduação entre o setor público e o privado é reveladora do rumo que seguiu o ensino superior no país e de sua atual configuração: 
enquanto as matrículas de graduação, desde meados dos anos 1970, encontram-se massivamente nas instituições privadas de ensino superior, ${ }^{3}$ as de pós-graduação, desde os seus primórdios, se mantêm majoritariamente em universidades públicas (BALBACHEVSKY, 2005).

O aumento do número de titulados mestres e doutores reflete na mudança do perfil dos docentes de ensino superior no país. Em 1990, os titulados mestres e doutores representavam, respectivamente, 21,1\% e $12,6 \%$ do total de 131.641 funções docentes (SAMPAIO, 2000). Vinte anos depois, em 2010, os mestres correspondiam a 37,7\% e os doutores a 28,4\% de um total de 345.335 funções docentes ${ }^{4}$ (BRASIL, 2015b). Como se vê, em duas décadas o mercado para a docência no ensino superior não só dobrou de tamanho como também se tornou presumivelmente mais qualificado (CALDERON, 2000). Embora o aumento dos percentuais de docentes com mestrado e com doutorado seja um efeito imediato da expansão da oferta de programas de pós-graduação e do crescimento do número de titulados em uma dinâmica de retroalimentação desencadeada nas últimas décadas, outro fator importante para a ocorrência desse incremento é a regulamentação do ensino superior desde o início da redemocratização do país.

Os princípios gerais determinados na Constituição de 1988 e as normativas legais especificadas na Lei de Diretrizes e Bases da Educação - LDB - de 1996 ratificaram o entendimento de que as universidades são o locus da produção científica e intelectual, passando a exigir dessas instituições, sejam públicas ou privadas, que pelo menos um terço de seus docentes tenha título de mestre e/ou de doutor. ${ }^{5}$ Esse dispositivo legal, cuja obrigatoriedade de cumprimento ocorreu simultaneamente ao aumento do número de universidades no país, foi decisivo para ampliar o mercado de trabalho dos egressos dos programas de pós-graduação stricto senso e, logo, aumentar a demanda por eles no sistema de ensino superior, uma vez que a titulação se tornou, pelo menos na letra da lei, um requisito desejável, e até compulsório em algumas instituições, para atuar como docente (BALBACHEVSKY; CASTRO, 2008). Para se ter ideia da expansão desse mercado de trabalho, em 1980, havia 65 universidades no País, das quais 20 eram privadas; em 1990, já eram 95, das quais 40 eram privadas (SAMPAIO, 2000). Nos vinte anos seguintes, de 1990 a 2010, o número de universidades dobrou: 190 universidades, das quais um pouco mais da metade (101) é pública (BRASIL, 2014).

Há, todavia, algumas peculiaridades na ampliação desse mercado de trabalho para os docentes do ensino superior. A elevação progressiva da titulação dos docentes, embora geral ao sistema, notadamente a partir da primeira década deste século, atinge com intensidade variada o setor público e o privado. No setor público, as funções docentes com doutorado passaram de $35,9 \%$, em 2001 , para 49,9\%, em 2010; as funções docentes com mestrado cresceram menos, de $26,9 \%$ para $28,9 \%$, no

\section{3}

Em 1980, o setor privado já respondia por $64,3 \%$ do total de matrículas de ensino superior no país (SAMPAIO, 2000)

\section{4}

De acordo com o Cadastro Nacional de Docentes do Ensino Superior (MEC/Inep, 2005), boa parte dos docentes brasileiros atua em mais de uma instituição ao mesmo tempo. Por isso, ao se analisarem informações sobre vínculo institucional, deve-se falar em "funções docentes". A recorrente vinculação dos docentes, especialmente no setor privado, a mais de uma instituição de ensino superior faz com que o número de funções docentes seja sempre superior ao número de docentes. 5 A LDB de 1996, no capítulo relativo ao ensino superior, estabece que a universidade se caracteriza pela institucionalização da produção intelectual e por isso pelo menos um terço de seu corpo docente deve ser mestre ou doutor e igual proporção deles deve ser contratada em regime de tempo integral (BRASIL, 1996b). 
A Plataforma Lattes do CNPq integra bases de dados de currículos, de grupos de pesquisa e de instituições em um único sistema de informações. Engloba ações de planejamento, gestão e operacionalização do fomento do CNPq e de outras agências federais e estaduais, fundações estaduais de apoio à ciência e tecnologia, instituições de ensino superior e institutos de pesquisa. Os currículos da Plataforma Lattes são atualizados pelos próprios docentes em função de exigências dos processos de avaliação das universidades e das agências de fomento diante de solicitações de docentes pesquisadores para financiamento de projetos de pesquisa.

mesmo período. No setor privado, a maior progressão das funções docentes ocorreu no nível de mestrado, passando de 35,4\%, em 2001, para 43,1\% em 2010; no caso do doutorado, passaram de $12,1 \%$ para $15,4 \%$ no período. De forma inversamente complementar, no mesmo período as funções "com especialização" diminuíram em ambos os setores: no público, passou de $37,3 \%$ para $21,2 \%$, e no privado, onde predominavam em 2001 representando 52,5\% das funções docentes, caíram para 41,5\%, em 2010 (BRASIL, 2010).

Além de o percentual de funções docentes preenchidas por doutores no setor público ser, em 2010, três vezes maior que no setor privado, o regime de trabalho também difere de um setor para o outro. Enquanto, no setor público, 80,2\% das funções docentes estão em regime de tempo integral - o que não equivale, em termos percentuais, ao grau mais elevado de titulação, que é de pouco mais de $50 \%$-, no setor privado, o percentual é de $24 \%$. No regime de tempo parcial, encontram-se $12,9 \%$ das funções docentes do setor público e $28 \%$ do setor privado. Quanto às funções docentes no regime de trabalho horista, elas são residuais no setor público, representando apenas 6,8\%, mas persistem fortemente no setor privado: 48\% das funções docentes são de horistas (BRASIL, 2010). ${ }^{6}$

Em algumas universidades públicas, a perspectiva, a curto e a médio prazos, é que todos os docentes sejam doutores e a opção pelo regime de trabalho (integral ou parcial), diferentemente do que ocorre no setor privado, é uma prerrogativa do próprio docente aprovado em concurso público no momento de sua contratação. Na Universidade de São Paulo - USP - e na Universidade Estadual de Campinas - Unicamp, instituições às quais se vinculam os docentes pesquisados, quase a totalidade do corpo docente tem titulação mínima de doutor e trabalha em regime de dedicação exclusiva. ${ }^{7}$

É nesse quadro geral de expansão do sistema de ensino superior no país e, em especial, de ampliação do mercado de trabalho para a docência nesse nível de ensino, que se situa este trabalho sobre a circulação docente entre instituições públicas e privadas.

O recorte empírico do estudo consiste no exame dos percursos de formação acadêmica e das trajetórias de atuação profissional dos docentes que hoje atuam na Faculdade de Educação da USP - FE/USP e na Faculdade de Educação da Unicamp - FE/Unicamp. ${ }^{8}$ A fonte de dados da pesquisa é a Plataforma Lattes ${ }^{9}$ do Conselho Nacional de Desenvolvimento Científico - CNPq. Embora detenha um grande potencial como fonte de pesquisa, a Plataforma Lattes ainda é relativamente pouco explorada por pesquisadores. Em um breve levantamento, identificamos alguns estudos em áreas específicas do conhecimento que se utilizaram dessa plataforma como instrumento de pesquisa.

Dentre os trabalhos localizados, destacamos o de Cavalcanti e colegas (2008) sobre o perfil dos pesquisadores na área de odontologia 
no Conselho Nacional de Desenvolvimento no período 2003-2005 e para o qual se utilizaram da Plataforma Lattes para a construção do banco de dados. Outro trabalho que também faz uso da plataforma é o de Vieira, Eesslin e Silva (2011) sobre a produção científica na área de contabilidade dos docentes de três universidades federais da região Sul do país nos anos 2008 e 2009. Na área médica, encontramos o estudo de Oliveira e colegas (2011) sobre a produção científica de pesquisadores do CNPq nas áreas de nefrologia e de urologia no período de 2006 a 2008; o estudo recorre à Plataforma Lattes para ter acesso aos currículos de 39 pesquisadores e, a partir do exame de variáveis previamente selecionadas, analisa a produção científica dos pesquisadores nesses campos específicos do conhecimento. Citamos, ainda, o estudo recente de Almeida e colegas (2016) sobre a participação de pesquisadores estrangeiros no sistema nacional de produção científica. Também recorrendo à Plataforma Lattes como instrumento de pesquisa, os autores analisam os currículos desses pesquisadores, identificando sua distribuição no sistema universitário brasileiro.

Neste estudo, selecionamos na Plataforma Lattes os cadastros dos currículos dos docentes das faculdades de Educação da USP e da Unicamp em dois momentos: segundo semestre de 2011 e primeiro semestre de 2013. Analisamos 190 currículos Lattes - 107 de docentes da FE/USP e 83 de docentes da FE/Unicamp. Os números equivalem à totalidade dos professores na ativa nas duas instituições na ocasião da pesquisa (SANCHEZ, 2013).

A partir dos dados fornecidos pelos professores em seus currículos Lattes identificamos as instituições de ensino superior onde eles obtiveram a formação acadêmica - desde a graduação ao doutorado - e, quando o caso, atuaram como docentes até ingressarem na FE/USP ou na FE/Unicamp. O estudo propõe conhecer a abrangência e a intensidade do que denominamos "circulação docente" entre instituições públicas e privadas nos percursos de formação acadêmica e nas trajetórias de atuação profissional dos/as professores/as e identificar as principais modalidades de manifestação desse fenômeno. Procuramos ainda apontar semelhanças e diferenças nas trajetórias dos docentes pesquisados vinculados a uma ou a outra instituição e, com base nelas, sugerir a existência de padrões de circulação docente no sistema de ensino superior.

O presente texto está organizado em três seções, além desta introdução. Na primeira parte, apresentamos, de forma breve, o desenvolvimento do ensino superior no estado de São Paulo e a sua participação do sistema nacional; na segunda, discutimos os principais resultados da pesquisa da perspectiva da circulação dos/das docentes entre instituições de ensino superior públicas e privadas ao longo de suas trajetórias de formação graduada e pós-graduada e de atuação profissional e, na terceira, fazemos as considerações finais. 
Os resultados deste estudo visam a contribuir para ampliar o conhecimento sobre os processos de expansão, estratificação e hierarquização do sistema de ensino superior no Brasil nas últimas décadas e, notadamente, sobre a circulação docente entre instituições públicas e privadas de ensino superior.

\section{O ENSINO SUPERIOR PAULISTA NO CONTEXTO NACIONAL}

A expressiva participação do estado de São Paulo no sistema nacional de ensino superior - concentra em torno de $27 \%$ do total de matrículas e um quarto do montante de instituições - é um fenômeno conhecido e relativamente registrado (SAMPAIO, 2000; SCHWARTZMAN, 1988; DURHAM, 2003). Iniciado no final da década de 1960, a expansão do sistema paulista se deu por meio de dois processos simultâneos e complementares: a interiorização das instituições de ensino superior e o crescimento da participação da iniciativa privada na oferta desse nível de ensino. A instalação de instituições da USP em vários municípios do interior, a criação da Universidade Estadual Paulista "Júlio de Mesquita Filho" - Unesp, reunindo instituições isoladas em uma universidade com vários campi, a criação da Unicamp, em meados dos anos setenta, são acontecimentos significativos do processo de interiorização do ensino superior público no estado de São Paulo. No mesmo período, e pour cause, o ensino superior privado começou a se desenvolver no interior, com a instalação de faculdades privadas no entorno de instituições públicas recém-criadas. Ao contrário destas - gratuitas, em geral mais seletivas e detentoras de maior prestígio acadêmico -, as instituições privadas visavam a atender à crescente demanda de ensino superior que o setor público, embora também em expansão no estado, não era capaz de suprir (SAMPAIO, 2000). ${ }^{10}$

Em geral, as instituições privadas criadas nos anos 1970 eram iniciativas de professores que já atuavam no ramo da educação no nível fundamental e/ou secundário. Organizadas como faculdades isoladas, essas instituições ofereciam cursos de baixo custo e de fácil acesso (SAMPAIO, 2000). Entre os anos 1990 e 2000, muitas dessas instituições transformaram-se em universidades e, bem mais recentemente, algumas delas foram incorporadas, mediante processos de aquisição e fusão, por grandes grupos educacionais que atuam no ensino superior brasileiro desde a primeira década deste século (SAMPAIO, 2014).

Atualmente, contando com quase 600 instituições e com mais de 1,7 milhão de matrículas de ensino superior, São Paulo é o estado que mais emprega docentes nesse nível de ensino, respondendo por $23 \%$ do total de funções docentes do sistema nacional (Quadro 1). Também no âmbito da pós-graduação stricto sensu (mestrado, mestrado profissional e 
doutorado), o estado concentra mais de um quarto das matrículas e pouco

mais de 20\% do total de programas de pós-graduação no país (Quadro 1).

QUADRO 1

INSTITUIÇÕES, MATRÍCULAS DE GRADUAÇÃO, PROGRAMAS DE PÓS-GRADUAÇÃO E FUNÇÃO DOCENTE NO ENSINO SUPERIOR POR DEPENDÊNCIA ADMINISTRATIVA. BRASIL E ESTADO DE SÃO PAULO. 2014

\begin{tabular}{|l|c|c|c|c|}
\hline \multirow{2}{*}{ INSTITUIÇÃo, MATRÍCULAS E FUNÇÃo DOCENTE } & \multirow{3}{*}{$\begin{array}{c}\text { BRASIL } \\
(\%)\end{array}$} & $\begin{array}{c}\text { TOTAL } \\
(\%)\end{array}$ & $\begin{array}{c}\text { PÚBLICO } \\
(\%)\end{array}$ & $\begin{array}{c}\text { PRIVADO } \\
(\%)\end{array}$ \\
\cline { 3 - 5 } & $\begin{array}{c}2.368 \\
(100)\end{array}$ & $\begin{array}{c}596 \\
(25,2)\end{array}$ & $\begin{array}{c}95 \\
(15,9)\end{array}$ & $\begin{array}{c}501 \\
(84,0)\end{array}$ \\
\hline Número de IES* & $\begin{array}{c}6.498 .000 \\
(100)\end{array}$ & $\begin{array}{c}1.723 .474 \\
(26,5)\end{array}$ & $\begin{array}{c}270.886 \\
(15,7)\end{array}$ & $\begin{array}{c}1.452 .588 \\
(84,3)\end{array}$ \\
\hline Matrículas graduação presencial & $\begin{array}{c}3.302 \\
(100)\end{array}$ & $\begin{array}{c}838 \\
(21,4)\end{array}$ & $\begin{array}{c}620 \\
(74,0)\end{array}$ & $\begin{array}{c}218 \\
(26.0)\end{array}$ \\
\hline Programas de pós-graduação mestrado e doutorado** & $\begin{array}{c}232.381 \\
(100)\end{array}$ & $\begin{array}{c}65.357 \\
(28,1)\end{array}$ & $\begin{array}{c}51.897 \\
(79,4)\end{array}$ & $\begin{array}{c}13.460 \\
(20,6)\end{array}$ \\
\hline Matrículas pós-graduação stricto sensu & 383.386 & $\begin{array}{c}88.434 \\
(23,0)\end{array}$ & $\begin{array}{c}24.385 \\
(28,0)\end{array}$ & $\begin{array}{c}64.049 \\
(72,0)\end{array}$ \\
\hline Funções docentes em exercício *** & $(100)$ & & & \\
\hline
\end{tabular}

Fonte: Elaborado pelas autoras a partir de dados oficiais (BRASIL, 2015a, 2015b).

* Instituição de Ensino Superior.

** Trata-se da soma dos programas de pós-graduação mestrado/doutorado (2.031) com os programas só de mestrado (1.207) e com os programas apenas de doutorado (64).

*** O número de funções docentes em exercício é maior que o número de docentes, pois um docente pode atuar em mais de uma instituição.

Embora, nos últimos anos, o setor público tenha ampliado a sua oferta de ensino superior no estado de São Paulo com a instalação de universidades federais e de novos campi da USP e da Unicamp, com a criação de escolas superiores de tecnologia estaduais e federais, o setor privado é, de longe, majoritário em número de instituições e de matrículas. Responde por $84 \%$ do total de instituições e por igual proporção de matrículas de ensino superior no estado. A situação, todavia, se inverte na pós-graduação: nesse nível é o setor público que oferece $74 \%$ do total de programas e responde por cerca de 80\% das matrículas (Quadro 1). A participação do setor público paulista na pós-graduação, embora expressiva, encontra-se um pouco abaixo da média nacional, conforme se constata no Quadro 1. Tal fato deve-se à forte presença, e relativa antiguidade, de universidades privadas no estado, especialmente confessionais, o que não se verifica com a mesma incidência em outras regiões do país.

Dentre os dez programas de pós-graduação mais oferecidos no estado de São Paulo, destaca-se a área de Educação, com 35 programas de mestrado/doutorado, ${ }^{11}$ dos quais 19 se vinculam a universidades privadas (BRASIL, 2015b).

É nessa configuração do ensino superior paulista, tradicionalmente marcado pela forte presença de instituições privadas e, mais recentemente, pelo aumento do número de programas de pós-graduação, que se inscreve este estudo. Por meio do exame das trajetórias de

11

Em 2014, a área de Educação contava com 73 programas de mestrado/ doutorado e 52 programas de apenas mestrado no país, dos quais $26 \%$ e $13,5 \%$, respectivamente, eram oferecidos por instituições localizadas no estado de São Paulo (BRASIL, 2015b). 
formação acadêmica e de atuação profissional de docentes vinculados a duas conceituadas universidades públicas paulistas - USP e Unicamp - amplia-se a compreensão sobre a relação entre setor público e setor privado no sistema paulista, notadamente no que tange à circulação de estudantes e de professores na educação entre instituições de ambos os setores.

\section{FORMAÇÃO ACADÊMICA E ATUAÇÃO PROFISSIONAL SEXO, ANO DE INGRESSO COMO DOCENTE E FORMAÇÃO ACADÊMICA}

Em ambas as faculdades de educação onde se realizou a pesquisa predominam mulheres no quadro docente. Na FE/USP, à época do levantamento, elas representavam 64,5\% de um total de 107 docentes e na FE/Unicamp, 60\% de um total de 83 professores na ativa. Considerando-se as variáveis sexo e ano de ingresso dos/das docentes nas respectivas instituições, constata-se a prevalência de mulheres desde as turmas mais antigas, nos anos 1970 e 1980. Assim, diferentemente de outras áreas, como direito e carreiras ligadas à saúde, em que o processo de feminilização ocorreu mais tardiamente, ou ainda se encontra em curso, como em áreas ligadas às engenharias e às tecnologias (ROSEMBERG, 1984; BRUSCHINI; LOMBARDI, 1999; LOPES; LEAL, 2005; GUEDES, 2008), os dados levantados corroboram estudos que indicam o pioneirismo dos cursos na área de educação na inclusão de mulheres no ensino superior no Brasil (BARROSO; MELLO, 1976; VIANNA, 2013).

Em ambas as faculdades, a grande maioria do corpo docente ingressou como professor/a antes dos anos 2000, sendo que as décadas de 1990 e de 2000 registraram os maiores contingentes de ingresso de docentes de ambos os sexos nas duas instituições. Do total de professores,

De acordo com informações obtidas com funcionários de recursos humanos da FE/USP, nos anos mais recentes, pós-2010, foram realizados na faculdade tanto concursos para preenchimento de vaga docente como processos seletivos para contratação de professores emergenciais Com efeito, a resolução 5972-10 tem permitido a contratação de professores por período determinado e com a finalidade de cobrir licenças/afastamentos de docentes efetivados. Cf Resolução n. 5872, de 27

set. 2010 , sobre contratação de professores por prazo indeterminado na USP. $69 \%$ ingressaram antes dos anos 2000 e, dentre as docentes, 57\% o fizeram. Na FE/Unicamp, 76\% dos docentes homens ingressaram antes do ano 2000 contra 54\% na FE/USP (Quadro 2). ${ }^{12}$ Assim, embora os professores homens ingressem em número menor que as docentes, como se vê a partir dos dados referentes a todas as décadas registradas, eles tendem a permanecer mais tempo na carreira; com efeito, entre os docentes homens, os que ingressaram há mais tempo são a maioria. Essa constatação sugere a existência de uma correlação perversa entre gênero, tempo de permanência na instituição e progressão na carreira docente. Todavia, para a demonstração dessa hipótese, são necessários dados que fogem ao escopo deste trabalho. ${ }^{13}$ 
QUADRO 2

GÊNERO E DÉCADA DE INGRESSO DE DOCENTES DA FE/USP E DA FE/UNICAMP. 2011 E 2013

\begin{tabular}{|c|c|c|c|c|c|c|}
\hline \multirow{2}{*}{$\begin{array}{c}\text { DÉCADA DE } \\
\text { INGRESSO }\end{array}$} & \multicolumn{2}{|c|}{ FE/USP* } & \multicolumn{2}{c|}{ FE/UNICAMP** } & \multicolumn{2}{c|}{ TOTAL } \\
\cline { 2 - 7 } & FEM. & MASC. & FEM. & MASC. & FEM. & MASC. \\
\hline 1970 & 4 & 3 & 1 & 1 & 5 & 4 \\
\hline 1980 & 13 & 8 & 11 & 9 & 24 & 17 \\
\hline 1990 & 17 & 9 & 18 & 15 & 35 & 27 \\
\hline 2000 & 25 & 15 & 15 & 5 & 40 & 20 \\
\hline 2010 & 4 & 2 & 4 & 3 & 8 & 5 \\
\hline Total & 63 & 37 & 49 & 33 & 112 & 70 \\
\hline
\end{tabular}

Fonte: Elaborado pelas autoras a partir de Sanchez (2013).

* Sete docentes da FE/USP não informam no Currículo Lattes o ano de ingresso na instituição.

** Um docente da FE/Unicamp não informa no Currículo Lattes o ano de ingresso na instituição.

Quanto ao período de formação acadêmica, 80\% dos/das docentes da FE/USP graduaram-se entre os anos 1960 e 1980, 77\% titularam-se mestres entre os anos 1980 e 1990, e 70\% tornaram-se doutores nos últimos vinte anos. Na FE/Unicamp, o período de formação é um pouco mais recente: apenas três docentes hoje na ativa graduaram-se ainda na década de 1960 (contra 10 da FE/USP); a maior parte deles (70\%) formou-se entre os anos 1970 e 1980, fez mestrado (78\%) entre as décadas de 1980 e 1990 e o doutorado (90\%) entre os anos 1990 e 2000.

Enquanto, na FE/USP, 40\% dos professores ingressaram nos anos 2000, na FE/Unicamp a renovação do quadro docente ocorreu uma década antes. $\mathrm{O}$ fato de o ingresso como docente na FE/Unicamp e o desenvolvimento da pesquisa de doutorado ocorrerem no mesmo período para uma parte significativa dos/das professores/as indica que o título de doutor foi obtido posteriormente à admissão deles e delas no quadro docente da instituição, o que não se verifica entre os docentes da FE/USP (Quadro 3). ${ }^{14}$

14

Desde 1998, com a reforma da carreira docente na Unicamp, o cargo inicial passou a ser o MS3, que deve ser ocupado apenas por professores com título de doutor. Antes da reforma, o ingresso na carreira podia ocorrer pelo cargo MS2 e até pelo MS1, que exigiam, respectivamente, mestrado e graduação. No ano de 2011, quando realizamos a pesquisa, $3,4 \%$ do quadro docente da Unicamp ocupavam o cargo MS2.

\section{QUADRO 3}

DÉCADA DE FORMAÇÃO ACADÊMICA (GRADUAÇÃO E PÓS-GRADUAÇÃO) E DE INGRESSO NAS INSTITUIÇÕES ONDE ATUAM. 2013

\begin{tabular}{|c|c|c|c|c|c|c|c|c|}
\hline \multirow{2}{*}{ DÉCADA } & \multicolumn{4}{|c|}{ FE/USP } & \multicolumn{4}{c|}{ FE/UNICAMP } \\
\cline { 2 - 10 } & GRAD. & MEST. & DOUT. & INGRESSO & GRAD. & MEST. & DOUT. & INGRESSO \\
\hline 1960 & 10 & 0 & 0 & 0 & 3 & 0 & 0 & 0 \\
\hline 1970 & 26 & 9 & 2 & 7 & $32^{* * * *}$ & 9 & 1 & 2 \\
\hline 1980 & 44 & 25 & 17 & 21 & 35 & 31 & 6 & 20 \\
\hline 1990 & 22 & 54 & 42 & 26 & 13 & 32 & 51 & 33 \\
\hline 2000 & 1 & 12 & 45 & 40 & 1 & 8 & 24 & 20 \\
\hline 2010 & 0 & 0 & 1 & 6 & 0 & - & 1 & 7 \\
\hline Total & $103 *$ & $100^{* *}$ & 107 & $100^{* * *}$ & 84 & $80^{* *}$ & 83 & $82^{* * *}$ \\
\hline
\end{tabular}

Fonte: Elaborado pelas autoras a partir de Sanchez (2013).

* Docentes que não informam ano da graduação.

** Docentes com doutorado direto.

*** Docentes que não informam ano de ingresso na instituição.

**** Docentes com duas graduações. 


\section{PERCURSOS ACADÊMICOS E TRAJETÓRIAS PROFISSIONAIS}

Na literatura sobre formação e trabalho de professores, a noção de trajetória de vida é recorrente; em geral, os estudos, baseados em pesquisas empíricas, tratam das possibilidades de trabalho e dos deslocamentos efetuados por docentes ao longo de suas carreiras. Nóvoa (1992), em um trabalho que se propõe síntese, agrupou os estudos na área em nove categorias "não exclusivas”, conforme ressalta, em função de seus objetivos e eixos de análise. Ao descrever as categorias, o autor chama nossa atenção para a multiplicidade de interesses, concepções e estratégias que se acomodam sob a designação de "histórias de vida" nesses estudos. Para Nóvoa, embora essa variedade não constitua em si um problema, uma vez que possibilita, segundo ele, ampliar os recursos disponíveis para o trabalho de investigação científica, ela pode, ainda de acordo com o autor, estar na origem das dificuldades e dos equívocos das práticas pouco consistentes e das metodologias pouco rigorosas de pesquisa (NÓVOA, 1992).

Huberman (1992), a partir da análise de estudos empíricos sobre trajetória docente, propõe um modelo para os ciclos de vida profissional dos professores a partir de seus anos de atividade. Haveria, segundo o autor, cinco fases vivenciadas pelo docente no seu percurso profissional: fase de ingresso ( 1 a 3 anos); fase de estabilização (4 a 6 anos); fase de diversificação (7 a 25 anos); fase de serenidade (25 a 35 anos) e, por fim, fase de desinvestimento (mais de 35 anos de docência). Segundo o autor, cada uma delas apresenta características próprias que podem atravessar a carreira no ensino e atingir a maioria dos docentes.

Para outros autores, dentre os quais Nogueira (2004), o estudo de trajetórias é uma opção metodológica que consiste no acompanhamento de uma situação escolar ao longo de um período. Nesse entendimento, as relações entre os percursos dos indivíduos no interior do sistema de ensino e o seu meio social de pertencimento são fundamentais.

De acordo com Nogueira (2004), embora o estudo das trajetórias escolares não constitua uma novidade na sociologia da educação, pois desde os anos de 1960 as relações entre os percursos dos indivíduos no sistema de ensino e seu meio social são foco de interesse dos sociólogos, foi somente a partir da década de 1980 que surgiu uma abordagem menos generalista e mais preocupada com a diversidade (relativa) dos destinos e das práticas escolares no interior de um mesmo meio social. Nessa perspectiva, segundo a autora, o interesse dos pesquisadores passou a recair sobre as trajetórias de vida escolar de indivíduos concretos e nos processos subjetivamente vividos e interpretados por eles. Mais recentemente, a partir dos anos de 1990, surgiu uma nova abordagem - o interesse por trajetórias atípicas, excepcionais, que escapam às regularidades estatísticas identificadas nos anos de 1950/1960. Desde então, de acordo com Nogueira, o “insignificante estatístico” teria 
se tornado "sociologicamente significativo", o que nos permitiria falar hoje de uma "sociologia das trajetórias escolares”. Tal como a sociologia da educação contemporânea, a "sociologia das trajetórias escolares” comporta pluralidade teórica e metodológica e a perceção comum de que a trajetória escolar não é completamente determinada pelo pertencimento a uma classe social, mas está associada a outros fatores, como dinâmicas familiares, características dos sujeitos etc., os quais confeririam algum grau de autonomia em relação ao meio social (NOGUEIRA, 2004).

Embora Nogueira se refira a trajetórias escolares de modo amplo - e não especificamente a trajetórias de docentes do ensino superior -, suas considerações sobre o fato de a trajetória estar associada a fatores outros que não exclusivamente o pertencimento a uma determinada classe social são, conforme veremos mais adiante, pertinentes para este estudo.

Ainda em relação ao entendimento da noção de "trajetória", Isaia (2000) considera que as trajetórias pessoais correspondem às fases de desenvolvimento de cada pessoa em função de parâmetros específicos de tempo, espaço e estilo de vida. Para o autor, o caminho do desenvolvimento pessoal deve ser analisado tanto em termos individuais como em termos grupais, uma vez que os sujeitos, em seus percursos, interagem com outros sujeitos com os quais compartilham dos mesmos parâmetros geracionais, construindo, assim, uma geração (ISAIA, 2000).

Os trabalhos mencionados, além de inspiradores, ilustram a complexidade da noção de trajetória ou de história de vida para os estudos na área da Educação. ${ }^{15} \mathrm{O}$ presente estudo, todavia, não se inscreve nessa tradição. Emprestamos do dicionário Novo Aurélio as definições dos termos "percurso" e "trajetória”. O primeiro refere-se ao ato ou ao efeito de percorrer um espaço; remete também às ideias de movimento, deslocamento e itinerário. “Trajetória”, por sua vez, refere-se "ao que atravessa”, à linha descrita ou percorrida por um corpo em movimento. Ambos os termos, portanto, remetem a trajeto, palavra definida como o "espaço que alguém ou algo tem de percorrer para ir de um lugar a outro”; “trajetória”, “percurso” (FERREIRA, 1999).

Embora os termos percurso, trajetória e trajeto sejam, segundo o dicionarista, sinônimos em nossa língua, utilizamos um ou outro ao tratarmos de momentos diferentes de vida. Preferencialmente, adotamos o termo "percurso" para descrever o deslocamento feito pelo/a docente para passar de um nível acadêmico a outro mais elevado ao longo de sua formação acadêmica. No percurso, compreendido desde a graduação à conclusão do doutorado, o/a docente pode ter, ou não, se deslocado entre espaços institucionais distintos, ou seja, de instituições públicas para privadas ou vice-versa. Por sua vez, o uso do termo “trajetória” engloba tanto o percurso de formação do/da docente como os deslocamentos que perspectiva de estudo que se utiliza das noções de trajetórias e trajetos. Cf. Moura e Vasconcelos (2011) sobre os estudantes cotistas da UnB. 
fez no exercício da atividade de professor até ingressar na instituição onde hoje se encontra.

Conforme se constata nas figuras 1 e 2 (abaixo), três quartos (75\%) dos docentes da FE/USP e mais da metade (56\%) da FE/Unicamp graduaram-se em instituições públicas. Em nosso estudo, o "significante sociológico" (NOGUEIRA, 2004) é o fato de $25 \%$ e $46 \%$ dos docentes da FE/USP e da FE/Unicamp, respectivamente, terem se graduado em alguma instituição particular; o fato evidencia a participação do setor privado no atendimento da demanda de ensino superior, especialmente no interior do estado de São Paulo, há pelo menos quatro décadas, período em que se graduou a grande maioria dos docentes pesquisados. Voltaremos a esses dados mais adiante.

No nível da pós-graduação, mais de $80 \%$ dos docentes da FE/Unicamp e da FE/USP obtiveram seus mestrados em universidades públicas e mais de $90 \%$ deles se titularam doutores também em universidades públicas (figuras 1 e 2).

Os docentes da FE/USP e da FE/Unicamp que realizaram a graduação e a pós-graduação em instituições privadas constituem um grupo bastante reduzido (figuras 1 e 2). Na FE/Unicamp, eles somam seis em um universo de 83 , ou seja, menos de $10 \%$; destes, dois titularam-se mestres e doutores em uma mesma instituição privada. Dentre os docentes da FE/USP a situação é parecida. Embora o número de docentes que se tiDesde os anos 1990, cresce o número de programas de pós-graduação oferecidos por universidades privadas, notadamente os mestrados na área de humanidades e. dentre eles, os na Educação. Hoje, 74 instituições privadas no estado de São Paulo oferecem 239 programas de pós-graduação, sendo que 19 delas oferecem programas de pósgraduação na área de Educação (BRASIL, 2015b). podem estar associados à baixa ocorrência de docentes de ambas as faculdades de Educação com pós-graduação no exterior, sugerimos: i) diminuição, no período de titulação da maior parte desses docentes, entre os anos 1990 e os 2000 , de incentivos das agências de fomento federais para financiar estudantes de mestrado no exterior especialmente de ciências humanas e educação; ii) a incipiente (até hoje) internacionalização da área. A demonstração dessas hipóteses requer, contudo, maior investigação. tulou mestre em instituições privadas seja um pouco maior (17 casos, o que equivale a $17 \%$ do total), no nível de doutorado, eles somam quatro (Figura 1). Os dados são coerentes com a ainda restrita participação do setor privado na oferta de programas de mestrado e de doutorado no período em que esses docentes cursavam a pós-graduação. Contudo, novas investigações são necessárias para averiguar se esse padrão se mantém mesmo após o crescimento contínuo, nas últimas décadas, da oferta de cursos pós-graduados no setor privado. ${ }^{16}$

Os dados indicam ainda o reduzido número de docentes da FE/USP e da FE/Unicamp que cursou a graduação e/ou a pós-graduação no exterior (figuras 1 e 2). Na FE/Unicamp quase todos os docentes titulados fora do país são estrangeiros, notadamente latino-americanos. Na FE/USP, a proporção de formados no exterior (graduação ou pós-graduação) é ainda menor comparativamente à FE/Unicamp. ${ }^{17}$ 


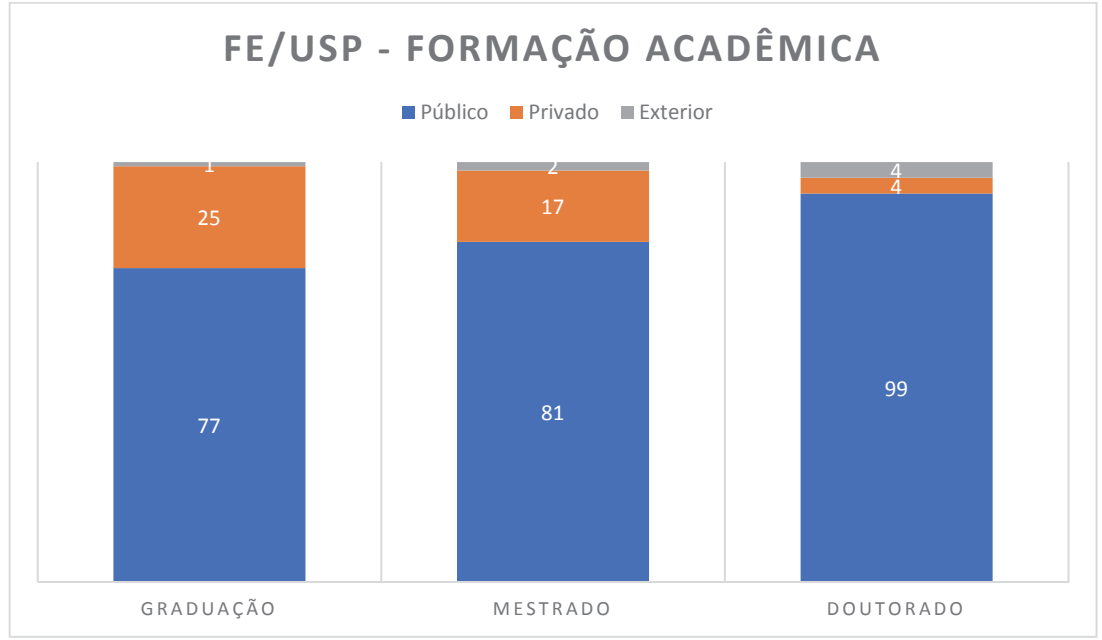

Fonte: Elaborada pelas autoras a partir de Sanchez (2013).

FIGURA 2

FORMAÇÃO ACADÊMICA DOS/DAS DOCENTES DA FE/UNICAMP SEGUNDO O LOCAL E DEPENDÊNCIA ADMINISTRATIVA DAS INSTITUIÇÕES

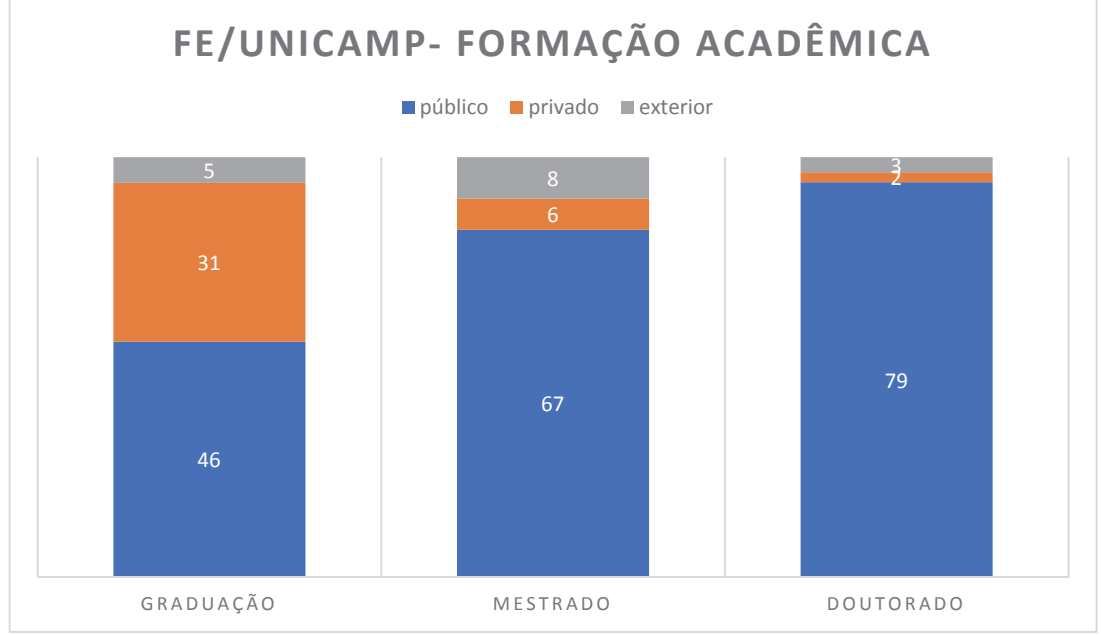

Fonte: Elaborada pelas autoras a partir de Sanchez (2013).

Feito o levantamento quantitativo, o passo seguinte foi identificar nominalmente as instituições de ensino superior frequentadas pelos docentes quando estudantes de graduação e de pós-graduação. Na FE/USP, como vimos, um quarto dos professores cursou a graduação em alguma instituição privada. Dentre eles, nove estudaram na Pontifícia Universidade Católica de São Paulo - PUC-SP - e seis na Pontifícia Universidade Católica de Campinas - PUC-Campinas; dois na Fundação Getúlio Vargas - FGV - e os demais distribuem-se em instituições privadas de diferentes tipos, de universidades a faculdades isoladas (Quadro 4). 
Conforme já apontado, o percentual de graduados em instituições privadas na FE/Unicamp é um pouco mais expressivo que na FE/USP. Dos 29 docentes daquela instituição que estudaram em instituições privadas, ${ }^{18}$ 19 o fizeram em universidades confessionais católicas - PUC-Campinas, PUC-SP e Pontifícia Universidade Católica do Rio de Janeiro - PUC-RJ. Esse elevado contingente se deve à antiguidade dessas instituições, criadas ainda em meados dos anos $1940,{ }^{19}$ quando o setor privado confessional funcionava como um setor paralelo ao público. ${ }^{20}$ Os demais docentes também graduados no setor privado distribuem-se por nove diferentes instituições - universidades, centros universitários e faculdades isoladas - as quais estão instaladas, em sua maioria, em cidades do interior do estado de São Paulo (Quadro 4).

No nível de pós-graduação, 16 docentes da FE/USP foram titulados mestres em instituições privadas, entre as quais figuram apenas três: PUC-SP, PUC-Campinas e PUC-RJ. Na FE/Unicamp, apenas seis docentes cursaram o mestrado em instituições privadas; além da PUC-Campinas e da PUC-SP, aparecem na lista a FGV, em São Paulo, e a Universidade Metodista de Piracicaba - Unimep. No doutorado, apenas a PUC-SP e a PUC-Campinas são citadas como instituição onde se titularam quatro docentes da FE/USP e dois da FE/Unicamp.

Em suma, entre os 20 docentes da FE/USP que fizeram a pós-graduação em instituições privadas, a PUC-SP lidera: são 14 títulos de mestre, de um total de 16, e todos os 4 de doutorado. Na FE/Unicamp é a PUC-Campinas que lidera: dos quatro docentes titulados no setor privado, três se titularam mestres e um doutor nessa universidade.

Situação mais frequente entre os docentes de ambas as instituições é realizar todo o percurso de formação acadêmica - da graduação ao doutorado - em universidades públicas. Essa situação corresponde, conforme indicado antes, a 58\% dos casos na FE/USP e a $48 \%$ dos casos na FE/Unicamp. 
QUADRO 4

IES PÚBLICAS E PRIVADAS NO PERCURSO FORMATIVO DOS DOCENTES DA FE/USP E DA FE/UNICAMP. 2011 E 2013

\begin{tabular}{|c|c|c|c|c|}
\hline \multirow{2}{*}{$\begin{array}{c}\text { NÍVEL DE } \\
\text { FORMAÇÃ̃O }\end{array}$} & \multicolumn{2}{|r|}{ FE/USP } & \multicolumn{2}{|c|}{ FE/UNICAMP } \\
\hline & IES PÚBLICAS & IES PRIVADAS & IES PÚBLICAS & IES PRIVADAS \\
\hline Graduação & $\begin{array}{l}77 \\
\text { USP (61); } \\
\text { Unicamp (4); } \\
\text { UFPR' (4); } \\
\text { Unesp (2); } \\
\text { UFCE"; } \\
\text { UFSJDR"II; } \\
\text { UFSCar'v; } \\
\text { UFMGv; } \\
\text { Instituto Municipal } \\
\text { de Ensino Superior } \\
\text { de São Manuel. }\end{array}$ & $\begin{array}{l}25 \\
\text { PUC-SP (9); } \\
\text { PUC-Campinas (6); } \\
\text { FVG (2); } \\
\text { Universidade Mackenzie; } \\
\text { Fac. de Ciências e Letras de } \\
\text { Sorocaba; Unitauvl; } \\
\text { Universidade do Vale do Paraíba; } \\
\text { Univ.de Barra Mansa; } \\
\text { Unicastelo; Univ. Fumec; } \\
\text { Faculdade de Engenharia e } \\
\text { Arquitetura; Universidade Santa } \\
\text { Úrsula. }\end{array}$ & $\begin{array}{l}47 \\
\text { Unicamp (21); } \\
\text { USP (15); } \\
\text { UFSCar (2); } \\
\text { Unesp; } \\
\text { UERJVII; } \\
\text { UFBA } \\
\text { UFJ"I; } \\
\text { UFMA; } \\
\text { UFPR; } \\
\text { UFMS } \\
\text { UFV'; } \\
\text { UFMG; }\end{array}$ & $\begin{array}{l}29 \\
\text { PUC-Campinas (13); } \\
\text { PUC-SP (5); } \\
\text { PUC-Rio (1); } \\
\text { Fac. de Santo André; } \\
\text { FAAPXII; } \\
\text { Unimarco }{ }^{x I V} ; \\
\text { Faculdade de Ituverava; } \\
\text { Unisinos }{ }^{\times v} \text {; } \\
\text { Univ. de Passo Fundo; } \\
\text { Centro Universitário } \\
\text { Moura Lacerda; } \\
\text { Fac. de Votuporanga; } \\
\text { Fac. Oswaldo Cruz. }\end{array}$ \\
\hline Mestrado & $\begin{array}{l}82 \\
\text { USP (61) } \\
\text { Unicamp (17) } \\
\text { UFMG (1) } \\
\text { UFSCar (1) } \\
\text { UFPR (1) } \\
\text { Unesp (1) }\end{array}$ & $\begin{array}{l}16 \\
\text { PUC-SP (14) } \\
\text { PUC-Campinas1) } \\
\text { PUC-Rio (1) }\end{array}$ & $\begin{array}{l}67 \\
\text { Unicamp (52) } \\
\text { USP (13) } \\
\text { UFSCar (1) } \\
\text { UnB }{ }^{\mathrm{xVI}}(1)\end{array}$ & $\begin{array}{l}6 \\
\text { PUC-Campinas (3) } \\
\text { PUC-SP (1) } \\
\text { FGV (1) } \\
\text { Unimep (1) }\end{array}$ \\
\hline Doutorado & $\begin{array}{l}99 \\
\text { USP (83) } \\
\text { Unicamp (14) } \\
\text { Unesp (2) }\end{array}$ & $\begin{array}{l}4 \\
\text { PUC-SP (4) }\end{array}$ & $\begin{array}{l}79 \\
\text { Unicamp (66) } \\
\text { USP(12) } \\
\text { Unesp (1) }\end{array}$ & $\begin{array}{l}2 \\
\text { PUC-Campinas (1); } \\
\text { PUC-SP (1) }\end{array}$ \\
\hline Total & \multicolumn{2}{|r|}{107} & \multicolumn{2}{|r|}{83} \\
\hline
\end{tabular}

Fonte: Elaborado pelas autoras a partir de Sanchez (2013).

' Universidade Federal do Paraná; "Universidade Federal do Ceará; "' Universidade Federal de São João del-Rei; Iv Universidade Federal de São Carlos; ' Universidade Federal de Minas Gerais; VI Universidade de Taubaté; vII Universidade do Estado do Rio de Janeiro; VIII Universidade Federal da Bahia; IX Universidade Federal de Juiz de Fora; ${ }^{x}$ Universidade Federal do Maranhão; XI Universidade Federal do Mato Grosso do Sul; XII Universidade Federal de Viçosa; XIII Fundação Armando Álvares Penteado; xIV Universidade São Marcos; ${ }^{x V}$ Universidade do Vale do Rio do Sinos; ${ }^{\mathrm{XV}}$ Universidade de Brasília;

Na FE/USP, dos 77 docentes que se graduaram em instituição pública, a grande maioria cursou a própria USP; seguem, empatados, em número de quatro, os docentes graduados na UFPR e na Unicamp e, em terceiro lugar, têm-se dois docentes formados pela Unesp. Os demais formaram-se em seis diferentes instituições públicas - cinco universidades federais e um instituto municipal (Quadro 4). Na FE/Unicamp, dos 47 docentes graduados em instituições públicas, 21 foram alunos da própria Unicamp, 15 da USP, dois da UFSCar e um da Unesp; os demais dispersamem-se oito universidades federais (Quadro 4).

No nível de pós-graduação, dos 82 docentes da FE/USP, 61 titularam-se mestres na própria USP, 17 na Unicamp e os demais em quatro diferentes universidades públicas: Unesp e UFSCar, UFPR e UFMG. Na FE/Unicamp, dos 67 docentes titulados mestres no setor público, 52 o fizeram na própria Unicamp, 13 na USP, um na UFSCar e outro na UnB. No doutorado, tanto entre os docentes da FE/USP como entre os da $\mathrm{FE} /$ Unicamp, as universidades públicas se restringem às três estaduais paulistas: USP, Unicamp e Unesp, esta com um número muito menor de casos. 
A partir do exame dos percursos de formação acadêmica dos docentes da FE/USP e da FE/Unicamp é possível depreender aspectos constitutivos da dinâmica entre setor público e setor privado - e no interior de cada um deles - no sistema de ensino superior do país.

O primeiro aspecto refere-se à organização do sistema, especificamente às funções complementares que cada um de seus setores desempenha. À medida que se eleva o nível de formação acadêmica, diminui o número de instituições privadas no percurso de formação dos docentes pesquisados. Enquanto, na graduação, o número e a diversidade de instituições privadas são relativamente consideráveis - cerca de 30 diferentes instituições participam desse nível de formação -, no doutorado, limitam-se a duas - PUC-SP e PUC-Campinas. Mas o mesmo fenômeno também se verifica no percurso de formação realizado apenas no setor público. O número e a variedade de universidades públicas citadas diminuem à medida que se avança na formação acadêmica dos docentes pesquisados. Numerosas e diversificadas na etapa da graduação desses docentes, as instituições públicas, sobretudo as universidades federais, tornam-se mais escassas no mestrado e desaparecem por completo no nível do doutorado.

O segundo aspecto diz respeito à circulação dos docentes pesquisados entre as duas universidades públicas estaduais - USP e Unicamp - ao longo de seus percursos formativos. Na FE/USP dos 81 docentes que fizeram o mestrado em universidades públicas, apenas 15,9\% se titularam na Unicamp; no nível de doutorado, dos 99 docentes com doutorado em uma universidade pública, apenas 13\% obtiveram o título na Unicamp. Na FE/Unicamp, os resultados são parececidos: dos 67 docentes que realizaram o mestrado no setor público, apenas 15,7\% são titulados pela USP; e dos 79 professores que cursaram o doutorado em universidades públicas, apenas $14,5 \%$ têm o título outorgado pela USP. Os percentuais, entre $13 \%$ e $16 \%$, evidenciam uma baixa circulação dos docentes pesquisados entre essas duas universidades ao longo de seus percursos formativos. Tampouco a Unesp, outra universidade estadual paulista, tem presença significativa na trajetória de formação dos docentes da FE/USP e da FE/Unicamp. Na FE/USP, a Unesp aparece como local de graduação, mestrado e doutorado de, respectivamente, dois, um e dois de seus docentes. Já entre os professores da FE/Unicamp, a Unesp aparece na trajetória de apenas dois docentes: um fez a graduação e o outro o doutorado.

O terceiro aspecto, em certa medida associado ao anterior, refere-se ao alto grau de endogenianos quadros docentes da FE/USP e da FE/ Unicamp. Dos docentes da FE/USP titulados em universidades públicas, 57\% e 77\% titularam-se, respectivamente, mestres e doutores na própria USP. Dentre os docentes da FE/Unicamp que realizaram a pós-graduação em universidades públicas, 64\% titularam-se mestres e 77\% doutores na própria Unicamp. Comparando os percursos acadêmicos dos docentes de 
ambas as faculdades de Educação, constatamos, entre os da FE/Unicamp, um trânsito maior por instituições privadas, especialmente no nível de graduação e no de mestrado, o que torna esse grupo de docentes um pouco menos homogêneo em termos de formação acadêmica que o grupo de professores da FE/USP.

\section{TRAJETÓRIAS DE ATUAÇÃO PROFISSIONAL}

Até ingressarem na FE/USP ou na FE/Unicamp, onde trabalha, a 21

Os dados não permitem inferir se esses professores eram concursados/ efetivos ou se exerceram a docência na condição de professor emergencial, ou seja, contratados mediante processo seletivo por um grande maioria dos docentes pesquisados atuou como professor(a) em período determinado. instituições de ensino superior públicas (em torno de 30\%) e privadas (mais de 50\%).

Dentre os docentes da FE/USP, pouco mais de um terço já havia lecionado em universidade pública. Ao todo, são 36 diferentes instituições públicas que aparecem em suas trajetórias profissionais, sendo que as mais citadas são: Unesp (citada por 20 docentes), Unicamp (citada por 13), UFSCar (citada por 5) e UFMA (citada por 4). No caso dos docentes da FE/Unicamp, um percentual um pouco menor (29\%) também já havia trabalhado em outras universidades públicas antes de ingressar nela. Dezoito diferentes universidades públicas constam de suas trajetórias profissionais. Unesp (13), USP (7), UFSCar (4), Universidade Federal de Uberlândia - UFU - (4) e Universidade Estadual de Londrina - UEL - (3) são as mais citadas. Nota-se que a Unesp e a UFSCar constam das trajetórias profissionais de um número signiticativo de docentes da FE/USP e da FE/Unicamp. Encontramos ainda tanto ex-professores da USP atuando como docentes hoje na Unicamp como a situação inversa (Quadro 5). ${ }^{21}$ 
INSTITUIÇÕES DE ENSINO SUPERIOR PÚBLICAS E PRIVADAS NAS TRAJETÓRIAS DE ATUAÇÃO PROFISSIONAL DOS DOCENTES DA FE/USP E DA FE/UNICAMP. 2011 E 2013

\begin{tabular}{|c|c|c|c|c|}
\hline $\begin{array}{l}\text { TRAJETÓRIA } \\
\text { PROFISSIONAL }\end{array}$ & \multicolumn{2}{|c|}{ FE/USP } & \multicolumn{2}{|c|}{ FE/UNICAMP } \\
\hline \multirow[t]{8}{*}{ IES públicas } & \multirow{2}{*}{\multicolumn{2}{|c|}{$34 \%$}} & \multirow{2}{*}{\multicolumn{2}{|c|}{$\begin{array}{l}18 \\
29 \%\end{array}$}} \\
\hline & & & & \\
\hline & Unesp & 20 & Unesp & 13 \\
\hline & Unicamp & 13 & USP & 7 \\
\hline & UFSCar & 5 & UFSCAR & 4 \\
\hline & UFMA & 4 & UFU & 4 \\
\hline & & & UEL & 3 \\
\hline & Outras & 32 & Outras & 13 \\
\hline \multirow[t]{8}{*}{ IES privadas } & \multirow{2}{*}{\multicolumn{2}{|c|}{$\begin{array}{l}69 \\
47 \%\end{array}$}} & \multirow{2}{*}{\multicolumn{2}{|c|}{$\begin{array}{l}69 \\
16 \%\end{array}$}} \\
\hline & & & & \\
\hline & PUC-SP & 8 & PUC-Campinas & 16 \\
\hline & Mackenzie & 6 & Unimep & 8 \\
\hline & Uniban & 5 & PUC-SP & 7 \\
\hline & Univ. São Francisco & 5 & UFS** & 7 \\
\hline & PUC-Campinas & 4 & Unimarco & 4 \\
\hline & Outras & 64 & Outras & 64 \\
\hline Total de IES ${ }^{* * *}$ & & 105 & & 87 \\
\hline
\end{tabular}

Fonte: Elaborado pelas autoras a partir de Sanchez (2013).

*Universidade Bandeirante de São Paulo; **Universidade Federal de Sergipe.

${ }^{* * *}$ A soma das IES não corresponde ao total de docentes pesquisados porque muitos lecionaram em mais de uma instituição ao longo de suas trajetórias profissionais e, muitas vezes, em mais de uma instituição simultaneamente.

Os dados mostram ainda que quase a metade dos professores da FE/USP (47\%) e a mesma quantidade dos docentes da FE/Unicamp (46\%) lecionaram em instituições de ensino superior privadas antes de ingressarem nas universidades onde hoje trabalham. Muitas vezes atuaram simultaneamente em mais de uma instituiçãode ensino superior.

Nas trajetórias profissionais dos docentes da FE/USP constam 64 diferentes instituições privadas; as mais citadas são PUC-SP, Universidade Mackenzie, Universidade São Francisco, Uniban e PUC-Campinas. No caso dos docentes da FE/Unicamp, constam de suas trajetórias 64 diferentes instituições privadas; as mais recorrentes são PUC-Campinas, Unimep, PUC-SP, Universidade São Francisco e Unimarco (Quadro 5).

Por meio da análise desses deslocamentos dos docentes da FE/USP e da FE/Unicamp entre instituições públicas e privadas revelam-se a segmentação e a hierarquia do sistema de ensino superior no país. Embora o sistema brasileiro não opere como o sistema de ensino superior norte-americano, em que a circulação dos docentes por diferentes instituições de ensino superior, notadamente por universidades de pesquisa, faz parte da construção da carreira acadêmica (GEIGER, 1985), o exame da trajetória de atuação profissional dos docentes pesquisados 
sugere a existência de ampla circulação deles por instituições de ensino superior públicas e privadas, estas especialmente localizadas no estado de São Paulo, antes de ingressarem nas universidades onde hoje se encontram.

\section{CONSIDERAÇÕES FINAIS}

Os percursos de formação acadêmica e as trajetórias profissionais dos docentes da FE/USP e da FE/Unicamp encontram-se fortemente imbricadas com o desenvolvimento do sistema de ensino superior no país e, de forma especial, com o do sistema paulista. Dois momentos são ilustrativos: a fase inicial do percurso de formação, ou seja, a graduação; e, na trajetória de atuação profissional, a fase que antecede o ingresso nas duas universidades estaduais.

Embora a maioria dos docentes pesquisados tenha cursado universidades públicas paulistas, especialmente no nível da pós-graduação, uma parcela significativa deles se graduou em universidades públicas de outros estados e outra, não menos expressiva, em uma grande gama de instituições privadas, notadamente paulistas. No caso dos docentes da FE/Unicamp, em especial, quase a metade graduou-se em alguma instituição privada do estado.

Constatamos ainda que a presença de universidades públicas de outros estados e de instituições privadas nos percursos formativos dos docentes pesquisados tende a diminuir (mas não a desaparecer) à medida que se avança no grau acadêmico; mais frequentes na graduação, elas tornam-se escassas no doutorado, evidenciando a própria dinâmica do sistema de ensino superior no país e os papeis diferenciados ocupados pelos setores público e privado e, no seu interior, seus diferentes segmentos.

Se os percursos de formação acadêmica dos docentes da FE/USP e da FE/Unicamp indicam uma circulação mais restrita deles, ainda na condição de estudantes, por instituições públicas e privadas, o mesmo não ocorre em relação às suas trajetórias de atuação profissional. O número expressivo e a diversidade de instituições - universidades, centros universitários e faculdades, públicas e privadas, laicas e confessionais, estaduais e federais, com e sem fins lucrativos - nas trajetórias profissionais dos docentes pesquisados evidenciam a existência de um robusto e consolidado mercado de trabalho docente no país e, em especial, no estado de São Paulo. Por outro lado, nessa circulação por diferentes tipos de instituições também se expressa a forte hierarquia que vigora em nosso sistema em termos de condições de trabalho (regime de trabalho e estabilidade), oportunidades de carreira, prestígio acadêmico e científico, etc. Não fosse essa percepção, os docentes pesquisados não teriam se dirigido para as universidades às quais se vinculam hoje. 
Em suma, por meio do exame das trajetórias individuais dos docentes pesquisados conseguimos captar fenômenos constitutivos do desenvolvimento do ensino superior no país e, em particular, no estado de São Paulo: a interiorização da oferta, os processos de privatização e de mercantilização que a acompanham, a expansão da pós-graduação e, com ela, o aumento do contingente de titulados mestres e doutores, a ampliação das oportunidades para o exercício da docência superior e também as condições desiguais de trabalho em que ele se realiza. Nos percursos de formação acadêmica e nas trajetórias de atuação profissional dos docentes da FE/USP e da FE/Unicamp, o sistema de ensino superior brasileiro revela-se segmentado e hierarquizado, conferindo novas nuances à já gasta dicotomia público e privado.

Os resultados obtidos na pesquisa instigam novas questões para outras investigações. Uma, entretanto, soa fundamental: em que medida as futuras gerações de docentes da FE/USP e da FE/Unicamp manterão essa relativa diversidade de formação acadêmica, notadamente no nível de graduação, e a diversificada atuação profissional em instituições públicas e privadas que caracterizam as trajetórias dos docentes pesquisados? A ampliação do ensino superior público, com a instalação de novas universidades federais, a expansão da pós-graduação em instituições públicas e privadas, a redução do tempo de formação pós-graduada e a titulação de doutores cada vez mais jovens são alguns fatores que certamente irão repercutir nas trajetórias de formação acadêmica e de atuação profissional dos futuros docentes. Possivelmente ocorrerão alterações nos padrões de circulação de estudantes e professores por instituições públicas e privadas, os quais identificamos neste trabalho, acenando no sentido de instaurar ainda maior endogenia institucional.

\section{REFERÊNCIAS}

ALMEIDA, Ana Maria F. et al. International faculty in a Brazilian university: international trajectories in a nationalized system of scientific production. In: YUDKEVICH, Maria; ALTBACH, Philip G.; RUMBLEY, Laura E. (Org.). International faculty in higher education: comparative perspectives on recruitment, integration, and impact. Nova York: Routledge, 2016. p. $50-75$

BALBACHEVSKY, Elizabeth. A pós-graduação no Brasil: novos desafios para uma política bemsucedida. In: SCHWARTZMAN, Simon (Org.). Os desafios da educação no Brasil. Rio de Janeiro: Nova Fronteira, 2005. p. 285-314.

BALBACHEVSKY, Elizabeth; CASTRO, Maria Helena Magalhães de. Experiências internacionales de reformas y evaluación de la educación superior y su impacto sobre la professión académica: Brasil (1995-2007). Revista de la Educación Superior, Cidade do México, v. 37, n. 145, p. 101-113, enero/marzo 2008.

BARROSO, Carmem Lucia de Melo; MELLO, Guiomar Namo. O acesso da mulher ao ensino superior brasileiro. Cadernos de Pesquisa, São Paulo, n. 15, p. 47-79, 1976.

BOSI, Antonio de Pádua. A precarização do trabalho docente nas instituições de ensino superior do Brasil nesses últimos 25 anos. Educação e Sociedade, Campinas, v. 28, n. 101, p. 1503-1523, set./dez. 2007. 
BRASIL. Ministério da Educação. Censo da Educação Superior. Resumo Técnico. Brasília, DF: MEC/Inep, 2010.

BRASIL. Ministério da Educação. Censo da Educação Superior 2014. Principais Resultados. Brasília, DF: MEC/Inep, 2015a.

BRASIL. Coordenação de Aperfeiçoamento de Pessoal de Nível Superior. Geocapes - Sistema de Informações Georreferenciadas, Brasília, DF: Capes, 2015b. Disponível em: <http://geocapes. capes.gov.br/geocapes>. Acesso em: 14 nov. 2016.

BRASIL. Lei n. 9.394, de 20 de dezembro de 1996. Estabelece as diretrizes e bases da educação nacional. Brasília, DF, 1996.

BRUSCHINI, Cristina; LOMBARDI, Maria Rosa. Médicas, arquitetas, advogadas e engenheiras: mulheres em carreiras profissionais de prestígio. Estudos Feministas, Florianópolis, v. 7, n. 1/2, p. 9-24, 1999.

CALDERÓN, Adolfo. Universidades mercantis: a institucionalização do mercado universitário em questão. São Paulo em Perspectiva, São Paulo, v. 14, n. 1, jan./maio 2000.

CAVALCANTE, Raika Augusta et al. Perfil dos pesquisadores da área de odontologia do Conselho Nacional de Desenvolvimento Científico e Tecnológico CNPq. Revista Brasileira de Epidemiologia, São Paulo, v. 11, n. 1, p. 106-113, mar. 2008.

DUARTE, Miriam Barros Assis. Fatores de pressão e comprometimento organizacional: um estudo com docentes de uma instituição de ensino superior privada. 2016. 80 f. Dissertação (Mestrado em Administração) - Fundação Municipal para Educação Comunitária, FUMEC, Belo Horizonte, 2016.

DURHAM, Eunice R. O ensino superior em São Paulo: diagnóstico. São Paulo: USP/Núcleo de Políticas Públicas, 2003.

FERREIRA, Aurélio Buarque de Holanda. Novo Aurélio XXI: o dicionário da língua portuguesa. 3. ed. Rio de Janeiro: Nova Fronteira, 1999.

GEIGER, Roger. Private sectors in higher education. Structure, function in eigth countries. Ann Arbor: The University of Michigan Press, 1986.

GEIGER, Roger. Hierarchy and diversity in American research universities. In: WITTOCH, Börnj; ELZINGA, Aant (Org.). The university research system: the public policies of the home of scientist. Estocolmo: Almqvist \& Wiksell, 1985.

GUEDES, Moema de Castro. A presença feminina nos cursos universitários e pós-graduações: desconstruindo a ideia da universidade como espaço masculino. História, Ciência e Saúde - Manguinhos, Rio de Janeiro, v. 15, 2008. Disponível em: <http://www.scielo.br/scielo. php?script=sci_arttext\&pid=S0104-59702008000500006>. Acesso em: 2 set. 2017.

HUBERMAN, Michael. O ciclo de vida profissional dos professores. In. NÓVOA, António (Org.). Vidas de professores. Porto: Porto, 1992. p. 31-61.

ISAIA, Silvia Maria de Aguiar. Professor universitário no contexto de suas trajetórias como pessoa e profissional. In: MOROSINI, Marília (Org.). Professor do ensino superior: identidade, docência e formação. Brasília: Inep, 2000. p. 21-33.

LOPES, Marta Julia Marques; LEAL, Sandra Maria Cezar. Feminização persistente na qualificação profissional da enfermagem brasileira. Cadernos PAGU, Campinas, v. 24, p. 105-125, jan./jun. 2005.

MARTINS, Carlos Benedito. A formação de um sistema de ensino superior de massa. Revista Brasileira de Ciências Sociais, Rio de Janeiro, v. 17, n. 48, p. 197-213, fev. 2002.

MONTAGNER, Ana Paula. Reestruturação da carreira docente do Magistério Superior (MS). Sínteses Revista Eletrônica do SIMTEC, n. 4 2012. Disponível em: http://www.sbu.unicamp.br/seer/ ojs/index.php/simtec/article/view/7316. Acesso em: 08 out. 2017.

MOSCHKOVICH, Marília; ALMEIDA, Ana Maria F. Desigualdades de gênero na carreira acadêmica no Brasil. Dados: Revista de Ciências Sociais, Rio de Janeiro, v. 58, n. 3, p. 749-789, 2015.

MOURA, Cristina P.; VASCONCELOS, Larissa F. L. Trajetórias, trajetos e "motilidade” na UnB. Antropolítica: Revista Contemporânea de Antropologia, Brasília, n. 32, p. 87-112, 2011. 
NEVES, Clarissa. Diversificação do sistema de educação terciária: um desafio para o Brasil. Tempo Social, São Paulo, v. 15, n. 1, p. 21-44, 2003.

NOGUEIRA, Maria Alice. Favorecimento econômico e excelência escolar: um mito em questão. Revista Brasileira de Educação, Rio de Janeiro, n. 26, p. 133-184, maio/ago. 2004.

NÓVOA, António. Os professores e as histórias da sua vida. In: NÓVOA, António (Org.). Vidas de professores. Porto: Porto, 1992.

OLINTO, Gilda. A inclusão de mulheres nas carreiras de ciência e tecnologia no Brasil. Inclusão Social, Brasília, v. 5, n. 1, p. 68-77, jul./dez. 2011.

OLIVEIRA, Eduardo A. et al. Perfil e produção científica dos pesquisadores do CNPq nas áreas de nefrologia e urologia. Jornal Brasileiro de Nefrologia, São Paulo, v. 33, n. 1, p. 31-37, 2011.

ROSEMBERG, Fúlvia. Afinal, por que somos tantas psicólogas? Psicologia: ciência e profissão, Brasília, v. 4, n. 1, p. 6-12, 1984.

SAMPAIO, Helena. Ensino superior no Brasil: o setor privado. São Paulo: Hucitec, Fapesp, 2000.

SAMPAIO, Helena. Privatização do ensino superior no Brasil: novas e velhas questões. In: SCHWARTZMAN, Simon (Org.). A educação superior na América Latina e os desafios do século XXI. Campinas: Editora Unicamp, 2014.

SANCHEZ, Ilara. A atuação docente no ensino superior brasileiro: migrações de universidades privadas para públicas. 2013. Dissertação (Mestrado em Educação) - Universidade Estadual de Campinas, Campinas, 2013.

SCHWARTZMAN, Simon. A educação superior na América Latina e os desafios do século XXI. Uma introdução. In: SCHWARTZMAN, Simon (Org.). A educação superior na América Latina e os desafios do século XXI. Campinas: Editora Unicamp, 2014.

SCHWARTZMAN, Simon. Brazil: opportunity and crisis in higher education. Higher Education, v. 17, p. 99-119, 1988.

SILVA, Maurício Teixeira. 0 poder disciplinar enquanto uma dimensão da cultura organizacional: um estudo multicascos em instituições de ensino superior privadas. 2016. Dissertação (Mestrado em Administração) - Universidade Federal do Paraná, Curitiba, 2016.

SIQUEIRA, Tânia Cristina Alves. Ensino superior privado: notas sobre o trabalho dos docentes nas instituições particulares de ensino superior em Brasília. Revista de Ciências Sociais, Fortaleza, v. 40 , n. 2 , p. $61-72,2009$.

UNIVERSIDADE DE SÃO PAULO. Resolução n. 5872, de 27 setembro 2010. Dispõe sobre contratação de professores por prazo indeterminado. São Paulo: USP, 2010. Disponível em: $<$ http://www.leginf.usp.br/?resolucao=consolidada-resolucao-no-5872-de-27-de-setembrode-2010>. Acesso em: 2 set. 2017.

UNIVERSIDADE DE SÃO PAULO. Anuário Estatístico da Universidade de São Paulo. Paulo, 2017 (Ano base 2016). Disponível em: <https://uspdigital.usp.br/anuario/AnuarioControle>. Acesso em: 15 fev. 2017.

UNIVERSIDADE ESTADUAL DE CAMPINAS. Anuário 2017 Estatístico da Universidade Estadual de Campinas (Ano base 2016). Disponível em: <http://www.aeplan.unicamp.br/anuario/2017/ anuario2017.pdf >. Acesso em: 13 fev. 2017.

VIANNA, Claudia Pereira. A feminilização do magistério na educação básica e os desafios para a prática e a identidade coletiva docente. In: YANNOULAS, Silvia C. (Org.). Trabalhadoras: análise da feminilização das profissões e ocupações. Brasília: Abaré, 2013. p. 159-180.

VIEIRA, Amanda Martins; ENSSLIN, Sandra Rolim; SILVA, Harley Almeida Soares. Perfil da produção científica dos docentes dos departamentos de contabilidade de três universidades federais do Sul do Brasil. Enfoque: Reflexão Contábil, Maringá, v. 30, n. 3, p. 44-59, 2011. 
HELENA SAMPAIO

Docente da Faculdade de Educação da Universidade Estadual de Campinas Unicamp -, Campinas, São Paulo, Brasil

hsampaio@uol.com.br

\section{ILARA SANCHEZ}

Doutoranda do Programa de Pós-graduação em Educação da Universidade

Estadual de Campinas - Unicamp -, Campinas, São Paulo, Brasil

ilarasanchez01@gmail.com 